\title{
Bulge Testing of Copper and Niobium Tubes for Hydroformed RF Cavities
}

\author{
H. S. Kim ${ }^{1, *}$, M. D. Sumption ${ }^{1}$, M. A. Susner ${ }^{1,2}$, H. Lim ${ }^{1,3}$, and E.W. Collings ${ }^{1}$
}

${ }^{1}$ Dept. of Materials Science and Engineering, The Ohio State University, Columbus, OH, USA

${ }^{2}$ Now at Oak Ridge National Laboratory, Oak Ridge, TN, USA

${ }^{3}$ Now at Sandia National Laboratories, Albuquerque, NM, USA.

*Corresponding author: H. S. Kim, Tel: +1 (614) 906-4812, Fax: +1 (614) 292-1537, Email: kim.3237@osu.edu

\begin{abstract}
The heat treatment, tensile testing, and bulge testing of $\mathrm{Cu}$ and $\mathrm{Nb}$ tubes has been carried out to gain experience for the subsequent hydroforming of $\mathrm{Nb}$ tube into seamless superconducting radio frequency (SRF) cavities for high energy particle acceleration. In the experimental part of the study samples removed from representative tubes were prepared for heat treatment, tensile testing, residual resistance ratio measurement, and orientation imaging electron microscopy (OIM). After being optimally heat treated $\mathrm{Cu}$ and $\mathrm{Nb}$ tubes were subjected to hydraulic bulge testing and the results analyzed. In the final part of the study finite-element models (FEM) incorporating constitutive (stress-strain) relationships analytically derived from the tensile and bulge tests, respectively, were used to replicate the bulge test. As expected, agreement was obtained between the experimental bulge parameters and the FEM model based on the bulge-derived constitutive relationship. Not so for the FEM model based on tensile-test data. It is concluded that a constitutive relationship based on bulge testing is necessary to predict a material's performance under hydraulic deformation.
\end{abstract}

Key words: SRF cavities, Hydroforming, Tube bulge test, FEM 


\section{Introduction}

Dozens of electron-synchrotron-based light source exist worldwide, all of them powered by radio frequency $(\mathrm{RF})$ cavities both for boosting the electrons to final energy and maintaining that energy in the storage ring. The goal of the accelerating cavity designer is to achieve the largest possible operating electric field gradient which implies a high quality factor, $Q$, and hence a low surface resistance, $R_{s}$. To that end early RF cavities were of polished high purity $\mathrm{Cu}$. The $R_{s}$ of a $\mathrm{Cu}$ cavity decreases with decreasing $T$ and $\rho$ until a limit is reached after which it is temperature independent and of order $\mathrm{m} \Omega$ [1]. To further reduce $R_{s}$ and increase $Q$ the cavity needs to be lined with or constructed from superconducting material. Currently the superconductor of choice is $\mathrm{Nb}$ whose $\mathrm{BCS}$-based $R_{s}$ is some 3 to 4 orders of magnitude smaller than that of $\mathrm{Cu}[2]$. For these reasons the synchrotrons of high energy particle physics are also powered superconducting RF (SRF) cavities [3].

Reference [4] presents an overview of SRF cavity fabrication. The process may begin with the preparation of a disc-shaped blank and the formation by pressing of a half-shell; or the preparation of a length of $\mathrm{Nb}$ tube followed by the spinning of back-to-back pairs of half-shells. A series of such half-shells are joined by electron-beam (EB) welding to form a multi-cell cavity. Numerous welded seams are required. For example a nine-cell cavity fabricated from half-shells would require some eighteen equatorial and iris seams. To circumvent this costly process hydroforming has been introduced by groups at Japan's High Energy Accelerator Research Organization (KEK) [5] and Gemany's Deutsche Elektronen-Synchrotron (DESY) [6-9] as a way of creating seamless multicell SRF cavities. Under hydroforming, a previously "necked" tube is locked in a die and formed into a series of cells by hydraulic pressure. 
For the design of cavities fabricated by hydroforming, the constitutive relationship of tubular materials should be properly determined to avoid the failure of materials. This study, based on a series of tests performed on $\mathrm{Cu}$ and $\mathrm{Nb}$ tubes, demonstrates the procedure needed to obtain the stress-strain relationship appropriate to hydroforming of SRF cavities.

\section{Outline}

Test Sample Preparation and Characterization: Samples removed from OFHC Cu tube were annealed at The Ohio State University (OSU) after which it was determined that the conditions corresponding to maximum tensile plasticity were characterized by maximum residual resistance ratio (RRR), and minimum randomly oriented grain size. Samples removed from $\mathrm{Nb}$ tube were heat treated at the Fermi National Accelerator Laboratory (FNAL), according to prior experience, in preparation for tensile testing. Constitutive (stress-strain) relationships were derived from the tensile results. Bulge Testing: The results of the tensile tests (above) were evaluated and optimally heat treated lengths of $\mathrm{Cu}$ and $\mathrm{Nb}$ tubes were subjected to hydraulic bulge testing. Constitutive (stress-strain) relationships were derived from the bulge-test results. Stress-strain curves based on the tensile- and bulge-test measurements were plotted and compared. Numerical Simulation of the Bulge Test and Discussion: Using the effective stressstrain results from the tensile and bulge test, respectively, bulge formation was numerically

simulated using finite-element modelling (FEM). The bulge parameters (heights and wall thicknesses) of the $\mathrm{Cu}$ and $\mathrm{Nb}$ tubes based on the tensile- and bulge-acquired stress-strain relationships are compared and the results discussed.

\section{Test Sample Preparation and Characterization}




\subsection{Preparation}

\subsubsection{OFHC Copper}

From a long piece of OFHC $\mathrm{Cu}$ tube, $63.5 \mathrm{~mm}$ OD and $1.65 \mathrm{~mm}$ wall thickness, purchased from ThyssenKrupp Materials, three types of samples were fabricated: (i) $240 \mathrm{~mm}$ long tubes for bulge testing, (ii) standard "dog-bone" style segments, $50 \mathrm{~mm}$ gauge length, for tensile testing [10] and grain size measurement, and ( iii) wire segments, $100 \mathrm{~mm}$ long, for residual resistance ratio (RRR) measurement. The samples were heat treated (HT) in flowing Ar for $2 \mathrm{~h}$ at $300-800^{\circ} \mathrm{C}$ (heated up at $5^{\circ} \mathrm{C} / \mathrm{min}$ and furnace cooled) using OSU's $3 \mathrm{in}$. Lindburg tube furnace for the tubes and a 2 in. Thermdyne Corporation tube furnace for the smaller samples.

\subsubsection{Reactor-Grade Niobium}

Eight pieces of "Reactor-Grade" Nb tube $240 \mathrm{~mm}$ long, $63.5 \mathrm{~mm}$ OD and $1.59 \mathrm{~mm}$ wall thickness were purchased from the Firmetal Co., Ltd., Shanghai, China. The analysis of the $\mathrm{Nb}$ tube is given in Appendix A. In preparation for bulge testing, tensile testing, grain size and RRR measurement several pieces of tube along with some tensile-test samples were heat treated for $3 \mathrm{~h} / 800^{\circ} \mathrm{C}$ and $2 \mathrm{~h} / 1000^{\circ} \mathrm{C}$ at the Fermi National Accelerator Laboratory (FNAL) under the guidance of Dr L. D. Cooley.

\subsection{Characterization}

\subsubsection{OFHC Copper}

RRR Measurement: It is well known that metallic purity, solid solution strengthening, and electron scattering (electrical resistivity) are closely related [11][12][13]. Thus it is expected that a metal's ductility will increase along with its residual resistance ratio, $R R R=R_{273 K} / R_{O K}=$ $R_{273 K} / R_{4.2 K}$. The latter is measured using the standard four-point technique while the wire sample is dunked alternately into ice-water and liquid He. Figure 1 shows $R R R$ versus $2 \mathrm{~h}$ HT 
temperature rising to a maximum at $500^{\circ} \mathrm{C}$ as $R_{4.2 \mathrm{~K}}$ passes through a corresponding minimum, presumably in response to a minimization of intragrain electron-scattering-center concentration. It has been suggested that during the initial stages of HT the increase of $R R R$ values is associated with the decrease of structural defects [14], while at higher HT temperatures the precipitation and redissolution of impurities would account for an increase in resistivity [15].

As an intermediate cooling step between $273 \mathrm{~K}$ and $4.2 \mathrm{~K}$ the sample may be immersed in liquid $\mathrm{N}$ which provides an opportunity for examining the use of a new resistance-ratio metric, herein designated $r r=R_{273 K} / R_{77 K}$. Figures 2(a) and 2(b) demonstrate that $r r$ which also maximizes at $500^{\circ} \mathrm{C}$ is directly related to $R R R$ according to $R R R=0.001 \cdot \exp (1.604 \cdot r r)$ within $50<R R R<300$, a useful range of values.

Grain Size Measurement: The microstructures of the tensile test samples were examined using orientation image mapping (OIM). Following standard procedures, surface grinding started with 320 grit $\mathrm{SiC}$ paper and continued through 1200 grit. The sample was then polished using 6 $\mu \mathrm{m}, 1 \mu \mathrm{m}$, and $0.05 \mu \mathrm{m}$ abrasives and etched using the 1:1:1 (volume) mixture of ammonium hydroxide, and hydrogen peroxide (3\%), and distilled water. Post polishing with colloidal silica was performed using a vibratory polisher. During HT the as-received elongated cold-worked grain structure quickly begins to recrystallize, Figure 3 . The small increase in grain size up to $500^{\circ} \mathrm{C}$ is followed by a rapid increase above that temperature, Figure 4.

Tensile Testing: For tensile testing a standard specimen [10] was cut from a tube wall parallel to the tube axis. Mounted in an MTS tensile test machine the sample was strained at a rate of $0.002 / \mathrm{s}$. The strain was measured using an MTS extensometer and data was recorded using the MTS software. The test results, in the format engineering stress versus engineering strain are plotted in Figure 5. 
The elongated cold-worked grains (Figure 3) of the as-received material along with dissolved impurities (low $R R R$, Figure 1) are responsible for its low ductility. Heat treatment up to $500^{\circ} \mathrm{C}$ results in recrystallization and a slight increase in grain size. It contributes to the improvement of formability as well as the increase of $R R R$ due to the decrease of structural defects during the recrystallization. Accompanying $\mathrm{HT}$ above $500^{\circ} \mathrm{C}$ are the precipitation and redissolution of impurities [14][15] resulting in solution strengthening accompanied by reductions in $R R R$ [16]. The results of the tensile tests are summarized in Table I. With regard to the sample $\mathrm{HT}$ for $2 \mathrm{~h} / 500^{\circ} \mathrm{C}$, the parameters of the constitutive relationship (in the Hollomon format $\left.\sigma=K \cdot \varepsilon^{n}[17]\right)$ are $K=573.30$ and $n=0.578$.

Summary: The results of relative resistance ratio ( $R R R$ and $r r)$ measurement, orientation imaging microscopy, grain size measurement, and tensile testing combine to show that the optimal heat treatment need to prepare an OFHC Cu sample for bulge testing $2 \mathrm{~h} / 500^{\circ} \mathrm{C}$.

\subsubsection{Reactor-Grade Niobium}

RRR Measurement: The $R R R$ measurements were made on small tensile-test type samples. The chemical analysis provided by the vendors (Appendix I) reveals the presence of several important impurities such as: $\mathrm{C}, 30 \mathrm{ppm}$; Fe, $20 \mathrm{ppm}$; O, $10 \mathrm{ppm}, \mathrm{Ni}, 7 \mathrm{ppm}$. It is therefore not surprising that the as-received $\mathrm{Nb}$ has a $R R R$ of 34 instead of the 300 usually requested for cavity-grade $\mathrm{Nb}$. After a $\mathrm{HT}$ of $3 \mathrm{~h} / 800^{\circ} \mathrm{C}$ the $R R R$ dropped to 25 , as some of the impurities entered solution, and remained there even after $2 \mathrm{~h} / 1000^{\circ} \mathrm{C}$.

Grain Size Measurement: OIM was carried out on samples removed from $\mathrm{Nb}$ tube. Following the above standard polishing procedures the samples were etched using a1:1:2 (volume) mixture of nitric acid, hydrogen fluoride and hydrochloric acid. An elongated coldworked grain structure was observed for the as-received sample, Figure 6. In addition, it exhibits 
inhomogeneous microstructure in the thickness direction. The rolling process for the fabrication of tubes contributes to the non-uniform distribution of plastic strain through the thickness, which leads to the inhomogeneous of driving force of recrystallization. Therefore, inhomogeneous microstructure was still observed after HT, Figure 6.

Tensile Testing: Tensile testing of the $\mathrm{Nb}$ samples took place at strain rates of $0.001 / \mathrm{s}$ (as-received) and 0.005/s (HT). The results of the tensile tests are depicted in Figure 7 and summarized in Table II. Clearly $2 \mathrm{~h} / 1000^{\circ} \mathrm{C}$ is the better of the two HTs. The parameters of the deduced constitutive relationship $\left(\sigma=K \cdot \varepsilon^{n}\right)$ are $K=314.18$ and $n=0.191$.

\section{Bulge Testing}

\subsection{Equipment and Measurement}

The equipment assembled for bulge testing, Figure 8, consists essentially of three parts: the hard tooling, the hydraulic pressurizing system, and data acquisition system. Both ends of the tube blanks are clamped between pairs of fixed "dies" using a clamping force of up to 45 tons. The tube ends are locked into the dies by lead-foil-wrapped sealing punches to which a force of up to 20 tons was able to be applied by an Enerpac hydraulic cylinder. The outer dies and the inner punches prevent axial movement of the tube blank during subsequent hydroforming. Hydraulic pressure (maximum 68.9 MPa) is applied to the tube blank via a through-hole in one of the sealing punches using an air assisted hydraulic pump from the Enerpac and measured by an Omega pressure sensor attached to a through-hole in the other punch. As the bulge forms in the free mid-segment of the tube its height is measure by a Keyence laser displacement sensor and its wall thickness measured by an Olympus ultrasonic thickness gauge. The data were collected and managed using a program in LabView. 


\subsection{Data Analysis of the Test Data}

In order to quantitatively evaluate the mechanical properties of a material to be deformed an accurate constitutive equation is needed. The constitutive equation is generally obtained from the true stress-strain curve of a sample after uniaxial tensile testing. But if hydroforming is the goal it is necessary to obtain an equivalent or effective stress-strain relationship for a material under multiaxial stress. The results of a bulge test can provide the necessary data. For analyzing the results several models embodying various assumptions have been proposed (e.g. [18][19][20]). Based on previous experience [21] we selected the analytical model of Koç [19] for calculating the effective stress-strain curve from the results of measurements of applied pressure, bulge diameter, and wall thickness. The analytical parameters are depicted in Figure 9 and listed below.

\section{Dimensional Parameters}

\section{Starting Dimensions}

$R_{0}=$ initial tube radius $(31.75 \mathrm{~mm})$

$t_{0}=$ initial tube thickness $(1.65 \mathrm{~mm})$

$w=$ distance between the dies (70 $\mathrm{mm}$, the "bulge width")

\section{Final Dimensions}

$t=$ wall thickness of the bulge

$\Delta R=$ radial expansion of the bulge (the "bulge height")

$R_{\theta} \equiv R_{0}+\Delta R$

$R_{Z}=$ radius of the spherical bulge (the surface of the bulge is assumed to be everywhere part of a sphere of radius $R_{Z}$ ). By geometry (see Figure 9) $R_{Z}$ is given by $\left[(w / 2)^{2}+\Delta R^{2}\right] / 2 \Delta R$ 
Based on the radii $R_{\theta}$ and $R_{Z}$ defined above, the hydraulic pressure, $p$, and the wall thickness of the bulge, the principal stresses in the longitudinal $\left(\sigma_{\mathrm{z}}\right)$ and circumferential $\left(\sigma_{\theta}\right)$ directions are given by:

$$
\sigma_{z}=p R_{\theta} /(2 t), \quad \sigma_{\theta}=p R_{\theta} / t-\sigma_{z} R_{\theta} / R_{z}
$$

in which the force equilibrium at the top of the bulged tube was used, and the stress in the thickness direction was ignored.

The circumferential $\left(\varepsilon_{\Theta}\right)$ and thickness strains $\left(\varepsilon_{t}\right)$ are given by:

$$
\varepsilon_{\theta}=\ln \left(R_{\theta} / R_{0}\right), \quad \varepsilon_{t}=\ln \left(t / t_{0}\right)
$$

Finally, the effective stress $(\bar{\sigma})$ and strain $(\bar{\varepsilon})$ can be obtained using von Mises yield criterion supposing isotropy as follows:

$$
\bar{\sigma}=\sqrt{{\sigma_{\theta}{ }^{2}-\sigma_{\theta} \sigma_{z}+\sigma_{z}^{2}}^{2}}, \quad \bar{\varepsilon}=2 / \sqrt{3} \sqrt{\varepsilon_{\theta}^{2}+\varepsilon_{\theta} \varepsilon_{t}+\varepsilon_{t}^{2}} .
$$

The effective stress and strain data so obtained may be plotted and fitted to the Hollomon [17] constitutive relationship, $\sigma=K \cdot \varepsilon^{n}$.

\subsection{Results of the Bulge Tests and Comparison of the Bulge- and Tensile Results}

By way of example, Figure 10 depicts the OFHC $\mathrm{Cu}$ tube bulged tested after HT for $2 \mathrm{~h} / 500^{\circ} \mathrm{C}$. Selected bulge test results for $\mathrm{OFHC} \mathrm{Cu}$ after $\mathrm{HT}$ for $2 \mathrm{~h} / 500^{\circ} \mathrm{C}$ and the reactor-grade $\mathrm{Nb}$ after $\mathrm{HT}$ for $2 \mathrm{~h} / 1000^{\circ} \mathrm{C}$ are shown in Tables III and IV, respectively. Using these data, and with the aid of the analytical model described above, corresponding flow stress curves were developed and fit to the Hollomon relationship $\sigma=K \cdot \varepsilon^{n}$ within $0.02<\varepsilon<0.60$. The results for the $\mathrm{OFHC} \mathrm{Cu}$ and the reactor-grade $\mathrm{Nb}$ are shown in Figures 11 and 12, respectively. Also 
included for comparison are the fitted tensile test results for the $\mathrm{Cu}$ and the $\mathrm{Nb}$, respectively. The Hollomon parameters for all the fits are listed in Table V. This deviation between the results from uniaxial and biaxial stress state may stem from the crystallographic properties of the material and its mode of deformation. Therefore, the tube bulge test which embodies more accurate deformation behavior is necessary for the successful design of a SRF cavity relating hydroforming process.

\section{Numerical Simulation of the Bulge Test}

Numerical simulation is widely used to predict the deformation behavior and design the process parameters because of its speed and efficiency. Most hydroforming simulations are performed using commercial finite-element programs such as ABAQUS, PAM-STAMP, and LSDYNA. Numerical simulations of the hydroforming of tubular materials embody two main aspects. First, A method for determining the loading path (i.e., axial feeding) has been researched [22][23]. In this case, the axial feeding forces act at the both tube ends. Therefore, the loading path is important for obtaining the final form without wrinkling or buckling. The second aspect is related to the use of correct materials laws and parameters including flow curve and anisotropic properties [24][25]. In this study, the more accurate materials parameters were determined using numerical simulation analysis.

Finite element modelling (FEM) of the tube bulge test was performed using commercially available ABAQUS/explicit software. The axisymmetric cross-section of the tube was modeled considering the geometric symmetry due to the computational efficiency compared to the 3D model. Dies that applied axial and radial constraints to the tube ends prevented axial feeding. Four-noded axisymmetric solid elements (CAX4R) were used for the bulge-forming 
simulation with 4 element layers through the thickness. The input to the model comprised the elastic and plastic properties. The elastic properties of materials used for the simulation are given Table VI. The plastic property inputs were the $K$ and $n$ values listed in Table V. The results of the simulations expressed in terms of bulge height, $\Delta R$, and bulge thickness, $t$, versus pressure for the $\mathrm{OFHC} \mathrm{Cu}$ tube and the reactor-grade $\mathrm{Nb}$ tube are displayed in Figures 13 and 14. The three curves in each figure compare the experimental results ("Experiment") with the computational results based on the tensile-derived (Tensile Test) and bulge-derived (Bulge Test) $K$ and $n$ values.

Since they are actually derived from bulge-test data, the Bulge Test curves should replicate the Experimental curves and they do so within the stated model approximations up to pressures of about $10 \mathrm{MPa}$. Not so for the curves labelled Tensile Test which, derived from uniaxial tensile data, do not consider deformation under multiaxial stress.

Figures 13 and 14 show the bulge-based numerical simulation and experimental results tending to diverge at pressures above about $10 \mathrm{MPa}$ and approach the burst pressure. It may be caused by the anisotropic properties or localized deformation as the pressure approaches the burst pressure. During the calculation of flow stress curve using the analytical model, it assumed that the material is isotropic. However, the orientation of the material will change during deformation. Therefore, the material behavior under large strains may be not isotropic. In addition, the estimated burst pressure for the $\mathrm{Cu}$ tube based on its tensile strength and dimensions ([26][27]) is $12.6 \mathrm{MPa}$. Although the $\mathrm{Cu}$ tube used for the bulge test did not burst above the estimated pressure, the possibility of mechanical instability or localized necking is relatively high near the burst pressure [28][29]. The reactor grade $\mathrm{Nb}$ tube burst at 10.8 MPa, higher than the estimated pressure of $10.1 \mathrm{MPa}$. 


\section{Conclusion}

In order to create a useful constitutive relationship for the complex stress state that accompanies SRF cavity formation, bulge tests were performed on $\mathrm{Cu}$ and $\mathrm{Nb}$ tube samples that exhibited the greatest degrees of uniaxial elongation after HT. The data from the bulge tests and an accompanying set of tensile tests provided input to a finite-element model that recreated the bulge tests numerically. As expected the model based on the bulge test results fit the experimental data well at least at low stress levels safely below the bursting pressure. Not so for that based on the tensile results. The results of the study emphasize the importance of for bulge testing rather than tensile testing when deriving the constitutional relationships eventually needed for modelling the hydroforming of $\mathrm{Nb} \mathrm{SRF}$ cavities.

\section{Acknowledgements}

Dr Lance D. Cooley, selected the Nb tube heat treatment conditions and arranged for the heat treatments to be carried out at the Fermi National Accelerator Laboratory, Batavia, IL, USA. The research was supported by the United States Department of Energy, Office of High Energy Physics, under grant No. DE-SC0004217.

\section{References}

[1] . E.W. Collings, "Normal and Superconducting Radiofrequency Cavities for High Energy Particle Accelerators", Proc IEEE International Conference on Applied Superconductivity and Electronics Devices, Dec. 14-16, 2011, Sydney, Australia, pp. 326-329 (2012)

[2] P. Marchand, "Superconducting RF Cavities for Synchrotron LightSsources" Proc. EPAC 2004, Lucerne, Switzerland, pp.21-25

[3] www.Ins.Cornell.edu/Research/AP/../AboutSrf/BrochureOriginal.pdf 
[4] J. Delayen, "Cavity Fabrication",

http://uspas.fnal.gov/materials/08UMD/Cavity_Fabrication.pdf

[5] K. Ueno, "Nb/Cu Clad Seamless Cavity R\&D at KEK",

http://lcdev.kek.jp/InterRegional/JLAB2005Feb/Ueno-NbCuClad.pdf

[6] W. Singer, I. Gonin, I. Jelezov, H. Kaiser, T. Khabibuline, P. Kneisel, K. Saito, X. Singer, "Hydroforming of Tesla cavities at DESY". in EPAC, Vienna, Austria, 2000, pp. 327-329

[7] W. Singer, H. Kaiser, X. Singer, G. Weichert, I. Jelezov, T. Khabibuline, A.Skasyrskaia, P. Kneisel, T. Fujino, K. Saito, "Hydroforming of Superconducting TESLA Cavities", in The 10th Workshop on RF Superconductivity, Tsukuba, Japan, 2001, pp. 170-176

[8] W. Singer, X. Singer, K. Twarowski, I. Jelezov, T. Khabibuline, A.Skasyrskaia, P. Kneisel, "Hydroforming of $\mathrm{NbCu}$ Clad Cavities at DESY", in The 10th Workshop on RF

Superconductivity, Tsukuba, Japan, 2001, pp. 467-470

[9] W. Singer, "Hydroforming of Seamless Cavities", in ECFA-CLIC-ILC Meeting, SCRF Session, Geneva, 2010

[10] ASTM. E8, Standard test methods for tensile testing of metallic materials, Annual Book of ASTM standards, 3 (1997)

[11] E.W. Collings and H.L. Gegel (eds), "Physics of Solid Solution Strengthening", Plenum Press NY (1975)

[12] F.R. Fickett, “Oxygen Annealing of Copper: A Review”, Mater. Sci. Eng., 14 (1974) 199210

[13] F.R. Fickett, "Electrical Properties", in Materials at Low Temperatures, Chapter 5, Amer. Soc. Metals, Metals Park, OH (1983)

[14] I. M. Abdyukhanov, A. E. Vorobieva, E. A. Dergunova, M. V. Polikarpova, , K. A. Mareev, N. V. Traktirnikova, D. S. Novosilova, V. I. Pantsyrny, and P. A. Lukyanovet, "The RRR Parameter of the ITER Type Bronze-Route Cr-Coated Nb Sn Strands after Different Heat Treatments", IEEE Trans. Appl. Supercond., 22 (2012) pp. 4802804

[15] F.R. Fickett, "Oxygen-Free Copper at 4 K: Resistance and Magnetoresistance”, IEEE Trans. Magn. MAG-19 (1983) 228-231

[16] T.G. Nieh and W.D. Nix, "Embrittlement of Copper due to Segregation of Oxygen to Grain Boundaries, Met. Trans. A, 12 (1981) 893-901.

[17] J.H. Hollomon, “Tensile deformation”, Trans. AIME 162 (1945) 268-290 
[18] S. Fuchizawa, M. Narazaki, "Bulge Test for Determining Stress-Strain Characteristics of Thin Tubes", in Proc. $4^{\text {th }}$ Int. Conf. on Technology of Plasticity, Adv. Technol. Plasticity, (1993) pp. 488-493

[19] M. Koç, Y. Aue-u-lan, T. Altan, “On the Characteristics of Tubular Materials for Hydroforming -Experimentation and Analysis", Int. J. Machine Tools \& Manufacture, 41 (2001) 761-772

[20] Y.-M. Hwang, Y.-K. Lin, T. Altan, "Evaluation of Tubular Materials by a Hydraulic Bulge Test, Int. J. Machine Tools \& Manufacture, 47 (2007) 343-351

[21] H.S. Kim, M.D. Sumption, H. Lim, and E.W. Collings, "Analysis of Materials Properties of Niobioum Tube from the Results of a Virtual Bulge Test”, Adv. Cryo. Eng. (Materials), 58

(2012) 305-312

[22] M. Imaninejad, G. Subhash, and A. Loukus, "Loading path optimization of tube hydroforming process," Int. J. Machine Tools \& Manufacture, 45 (2005) 1504-1514

[23] Y. Aue-U-Lan, G. Ngaile, and T. Altan, "Optimizing tube hydroforming using process simulation and experimental verification," J. Mater. Process. Technology, 146 (2004) 137-143

[24] T. Sokolowski, K. Gerke, M. Ahmetoglu et al., "Evaluation of tube formability and material characteristics: hydraulic bulge testing of tubes," J. Mater. Process. Technology, 98 (2000) 34-40

[25] Y. M. Hwang, and C. W. Wang, "Flow stress evaluation of zinc copper and carbon steel tubes by hydraulic bulge tests considering their anisotropy," J. Mater. Process. Technology, 209 (2009) 4423-4428

[26] F. Klaas, "Aufweitstauchen von Rohren durch Innenhochdruckumformen”, Fortschrittsbericht VDI, Reihe 2: Fertigungstechnik Nr. 42, VDI-Verlag, Düsseldorf, (1987)

[27] M. Koç and T. Altan, "Prediction of Forming Limits and Parameters in the Tube Hydroforming Process”, Int. J. Machine Tools \& Manufacture, 42 (2002) 123-138

[28] Y. Lianfa and G. Cheng, "Determination of Stress-Strain Relationship of Tubular Material with Hydraulic Bulge Test", Thin-Walled Structures, 46 (2008) 147-154

[29] M. Strano and T. Altan, "An Inverse Energy Approach to Determine the Flow Stress of Tubular Materials for Hydroforming Spplications”, J. Mater. Process. Technology, 146 (2004) 92-96. 


\section{List of Tables}

Appendix A. Analysis of Reactor-Grade Niobium

Table I. Summary of the Tensile Properties of Heat Treated OFHC Cu

Table II. Summary of the Tensile Properties of Heat Treated Reacto- Grade Nb

Table III. Selected Bulge Test Results for OFHC Cu Heat Treated for $2 \mathrm{~h} / 500^{\circ} \mathrm{C}$

Table IV. Selected bulge Test Results for Reactor-Grade Nb Heat Treated for $2 \mathrm{~h} / 1000^{\circ} \mathrm{C}$

Table V. Hollomon Parameters Fitted to the Analyzed Effective Stress and Strain Data for Tensile-Tested and Bulge-Tested OFHC Cu and Reactor-Grade Nb

Table VI. Elastic Properties and Densities of $\mathrm{Cu}$ and $\mathrm{Nb}$ Metals for Simulation 


\section{List of Figures}

Figure 1. $\quad R R R$ as function of $2 \mathrm{~h}$ heat treatment temperature for $\mathrm{OFHC} \mathrm{Cu}$

Figure 2. (a) $r r$ as function of $2 \mathrm{~h}$ heat treatment temperature for $\mathrm{OFHC} \mathrm{Cu}$. (b) $R R R$ versus $r r$ within about $50<R R R<300$ for heat treated $\mathrm{OFHC} \mathrm{Cu}$

Figure 3. OIM micrographs of heat treated $\mathrm{OFHC} \mathrm{Cu}$

Figure 4. Grain size of $\mathrm{OFHC} \mathrm{Cu}$ as function of $2 \mathrm{~h}$ heat treatment temperature

Figure 5. Tensile properties of $\mathrm{OFHC} \mathrm{Cu}$ as-received and after heat treatment

Figure 6. OIM micrographs of heat treated reactor-grade $\mathrm{Nb}$

Figure 7. Tensile properties of reactor-grade $\mathrm{Nb}$ as-received and after heat treatment

Figure 8. Schematic of the equipment assembled for bulge testing

Figure 9. Parameters for analysis of the bulge test results

Figure 10. Bulge formed in the $\mathrm{OFHC} \mathrm{Cu}$ tube heat treated for $2 \mathrm{~h} / 500^{\circ} \mathrm{C}$

Figure 11. Effective stress/plastic strain curves for tensile- and bulge-tested heat treated $\mathrm{OFHC} \mathrm{Cu}$

Figure 12. Effective stress/plastic strain curves for tensile- and bulge-tested heat treated reactor-grade $\mathrm{Nb}$

Figure 13. For OFHC Cu, comparison of the Experimental results with simulated results based on constitutive relationships derived from the Tensile Test and the Bulge Test in terms of (a) bulge height, $\Delta R$, and (b) bulge thickness, $t$, versus applied pressure

Figure 14. For reactor-grade $\mathrm{Nb}$, comparison of the Experimental results with simulated results based on constitutive relationships derived from the Tensile Test and the 
Bulge Test in terms of (a) bulge height, $\Delta R$, and (b) bulge thickness, $t$, versus applied pressure 
Appendix A. Analysis of Reactor-Grade Niobium

\begin{tabular}{cccc}
\hline \hline Element & Content $(\%)$ & Element & Content (\%) \\
\hline $\mathrm{C}$ & 0.003 & $\mathrm{~N}$ & 0.0005 \\
\hline $\mathrm{O}$ & 0.001 & $\mathrm{H}$ & 0.0006 \\
\hline $\mathrm{Zr}$ & 0.004 & $\mathrm{Ta}$ & 0.02 \\
\hline $\mathrm{Fe}$ & 0.002 & $\mathrm{Si}$ & 0.0003 \\
\hline $\mathrm{W}$ & 0.0005 & $\mathrm{Ni}$ & 0.0007 \\
\hline $\mathrm{Mo}$ & 0.005 & $\mathrm{Hf}$ & 0.003 \\
\hline $\mathrm{Ti}$ & 0.0006 & $\mathrm{Nb}$ & balance \\
\hline \hline
\end{tabular}


Table I. Summary of the Tensile Properties of Heat Treated OFHC Cu

\begin{tabular}{ccccc}
\hline \hline $\begin{array}{c}\text { HT Temperature } \\
\left({ }^{\circ} \mathrm{C}\right)\end{array}$ & $\begin{array}{c}\text { Yield Strength } \\
(\mathrm{MPa})\end{array}$ & $\begin{array}{c}\text { Tensile Strength } \\
(\mathrm{MPa})\end{array}$ & $\begin{array}{c}\text { Uniform } \\
\text { elongation }\end{array}$ & $\begin{array}{c}\text { Grain Size } \\
(\mu \mathrm{m})\end{array}$ \\
\hline As received & 412 & 417.56 & 0.01 & - \\
\hline 300 & 60 & 243.34 & 0.46 & 14.2 \\
\hline 400 & 53 & 242.41 & 0.46 & 14.7 \\
\hline 500 & 38 & 236.77 & 0.49 & 17.1 \\
\hline 600 & 23 & 233.56 & 0.42 & 31.4 \\
\hline 700 & 27 & 233.40 & 0.35 & 58.7 \\
\hline \hline
\end{tabular}


Table II. Summary of the Tensile Properties of Heat Treated Reactor Grade Nb

\begin{tabular}{cccc}
\hline \hline $\begin{array}{c}\text { HT Temperature } \\
\left({ }^{\circ} \mathrm{C}\right)\end{array}$ & $\begin{array}{c}\text { Yield Strength } \\
(\mathrm{MPa})\end{array}$ & $\begin{array}{c}\text { Tensile Strength } \\
(\mathrm{MPa})\end{array}$ & $\begin{array}{c}\text { Uniform } \\
\text { elongation }\end{array}$ \\
\hline 800 & 171 & 214 & 0.12 \\
\hline 1000 & 140 & 189 & 0.23 \\
\hline \hline
\end{tabular}


Table III. Selected Bulge Test Results for OFHC Cu Heat Treated for $2 \mathrm{~h} / 500^{\circ} \mathrm{C}$

\begin{tabular}{ccc}
\hline \hline Pressure $(\mathrm{MPa})$ & Bulge height $(\mathrm{mm})$ & Wall thickness $(\mathrm{mm})$ \\
\hline 6.02 & 0.86 & 1.62 \\
\hline 7.00 & 1.44 & 1.59 \\
\hline 8.01 & 2.09 & 1.57 \\
\hline 9.02 & 2.72 & 1.53 \\
\hline 10.02 & 3.54 & 1.49 \\
\hline 11.01 & 4.72 & 1.43 \\
\hline 11.99 & 6.67 & 1.35 \\
\hline 13.01 & 9.64 & 1.23 \\
\hline \hline
\end{tabular}


Table IV. Selected bulge Test Results for Reactor Grade Nb Heat Treated for $2 \mathrm{~h} / 1000^{\circ} \mathrm{C}$

\begin{tabular}{ccc}
\hline \hline Pressure $(\mathrm{MPa})$ & Bulge height $(\mathrm{mm})$ & Wall thickness $(\mathrm{mm})$ \\
\hline 8.95 & 0.35 & 1.64 \\
\hline 9.49 & 0.59 & 1.62 \\
\hline 10.02 & 0.85 & 1.61 \\
\hline 10.50 & 1.27 & 1.59 \\
\hline 10.80 & 1.54 & 1.57 \\
\hline
\end{tabular}


Table V. Hollomon Parameters Fitted to the Analyzed Effective Stress and Strain Data for Tensile-Tested and Bulge-Tested OFHC Cu and Reactor Grade Nb

\begin{tabular}{cccc}
\hline \hline Material & Parameter & Tensile test & Bulge test \\
\hline \multirow{2}{*}{ OFHC Cu } & $K$ & 573.30 & 430.72 \\
\cline { 2 - 4 } & $n$ & 0.578 & 0.400 \\
\hline $\mathrm{Nb}$ & $K$ & 314.18 & 299.99 \\
\hline \hline
\end{tabular}


Table VI. Elastic Properties and Densities of $\mathrm{Cu}$ and $\mathrm{Nb}$ Metals for Simulation

\begin{tabular}{cccc}
\hline \hline Material & $\begin{array}{c}\text { Young's Modulus } \\
(\mathrm{GPa})\end{array}$ & Poisson's ratio & $\begin{array}{c}\text { Density } \\
\left(\mathrm{g} / \mathrm{cm}^{3}\right)\end{array}$ \\
\hline OFHC Cu & 115 & 0.31 & 8.90 \\
\hline $\mathrm{Nb}$ & 103 & 0.38 & 8.57 \\
\hline \hline
\end{tabular}




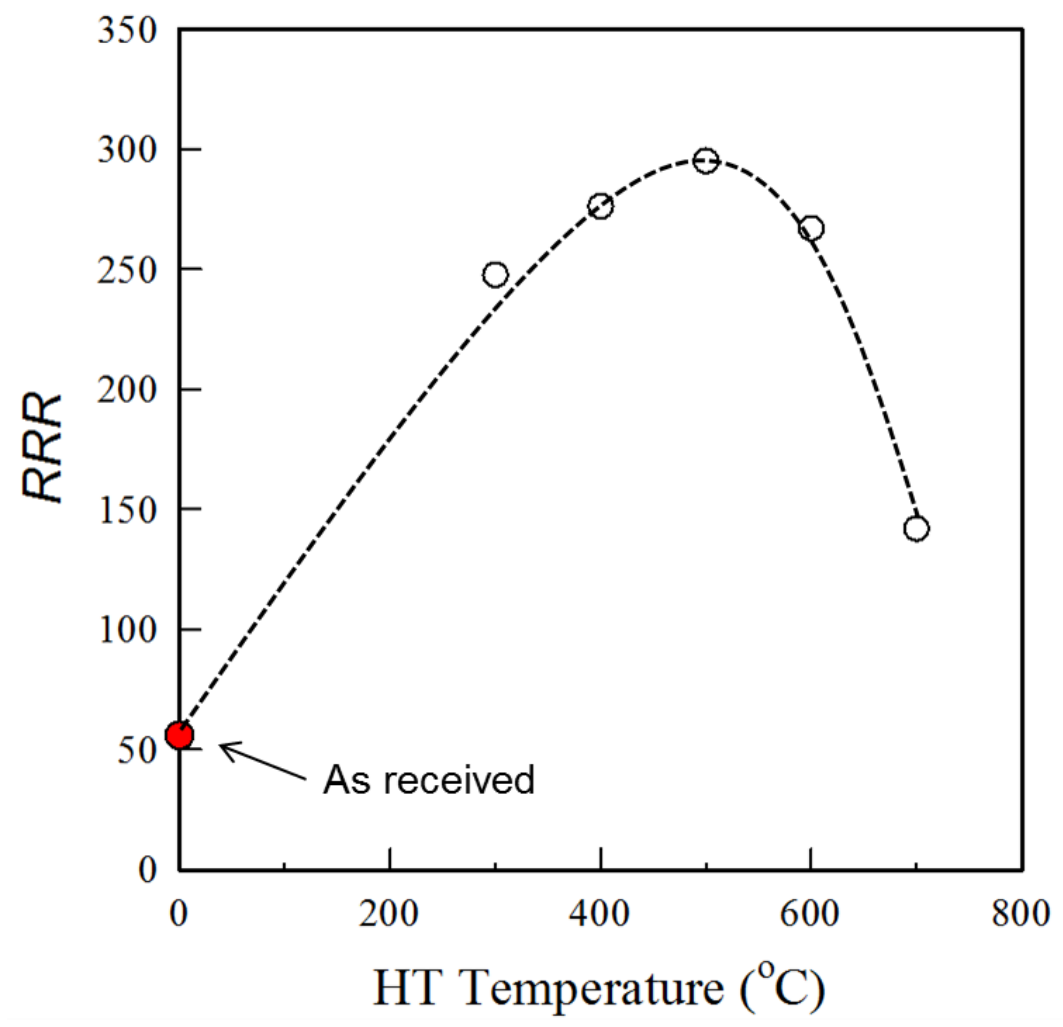

Figure 1. $R R R$ as f unction of $2 \mathrm{~h}$ heat treatment temperature for $\mathrm{OFHC} \mathrm{Cu}$ 

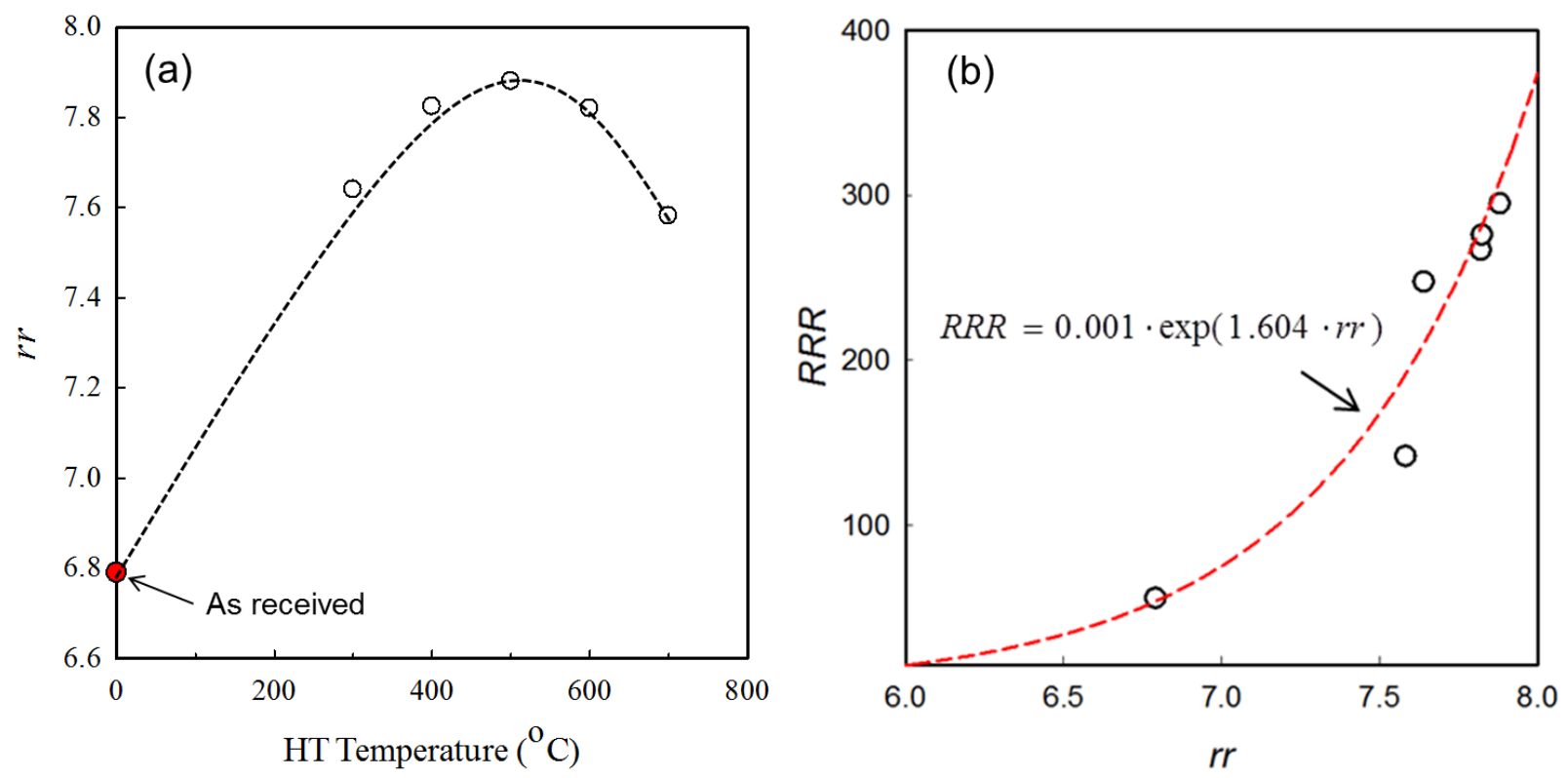

Figure 2. (a) $r r$ as function of $2 \mathrm{~h}$ heat treatment temperature for $\mathrm{OFHC} \mathrm{Cu}$. (b) $R R R$ versus $r r$ within about $50<R R R<300$ for heat treated $\mathrm{OFHC} \mathrm{Cu}$ 

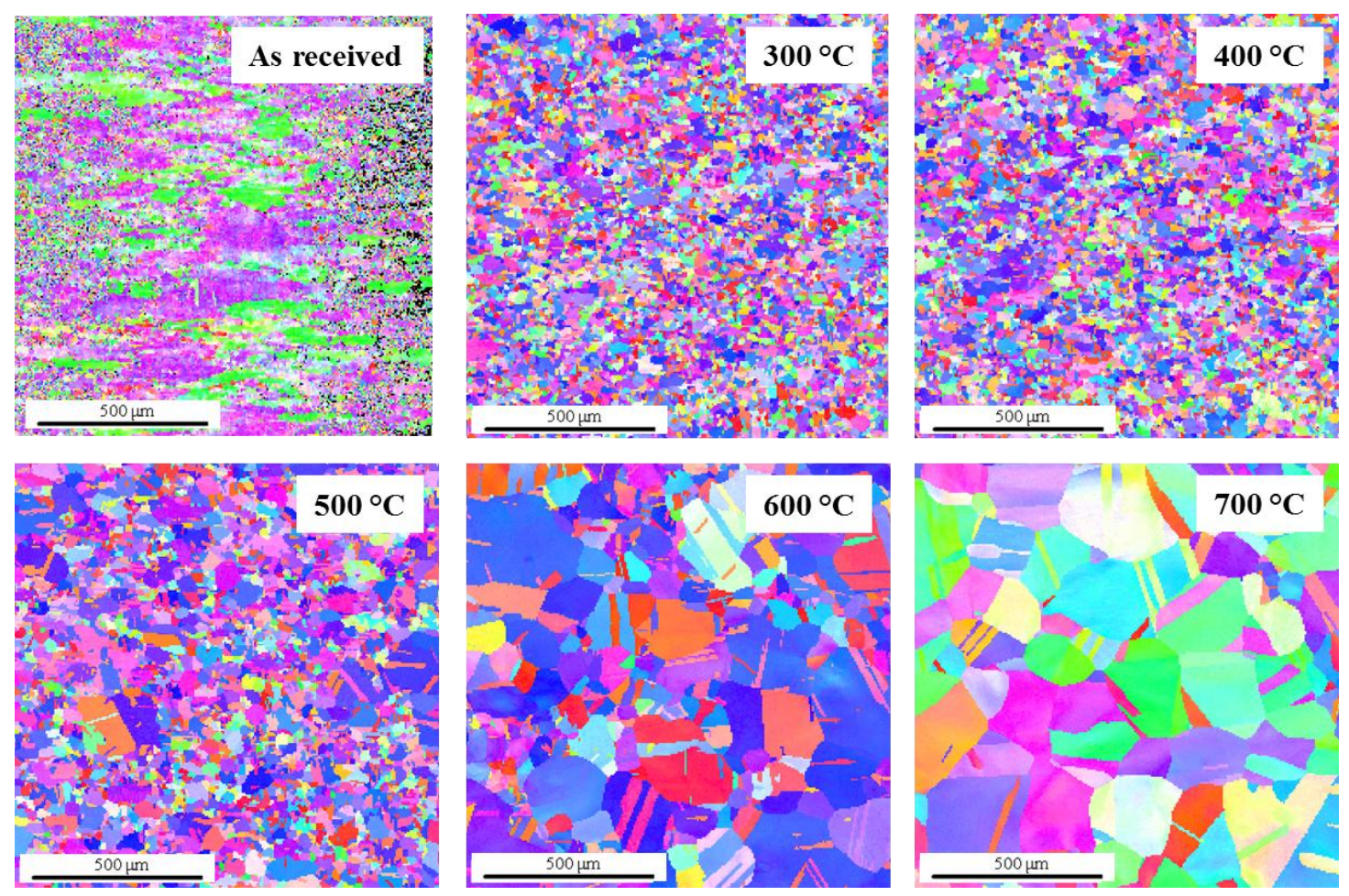

Figure 3. OIM micrographs of heat treated $\mathrm{OFHC} \mathrm{Cu}$ 


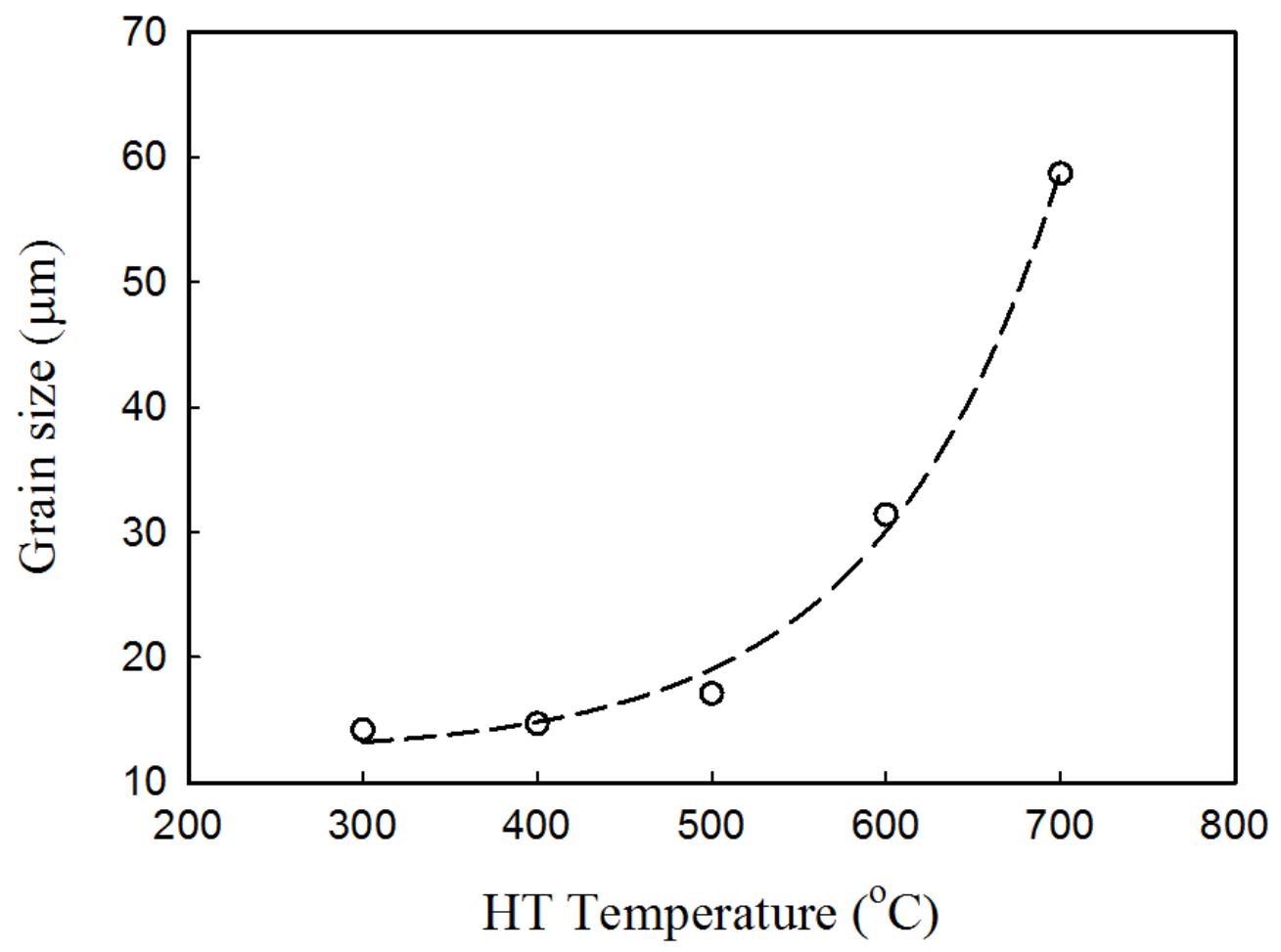

Figure 4. Grain size of $\mathrm{OFHC} \mathrm{Cu}$ as function of $2 \mathrm{~h}$ heat treatment temperature 


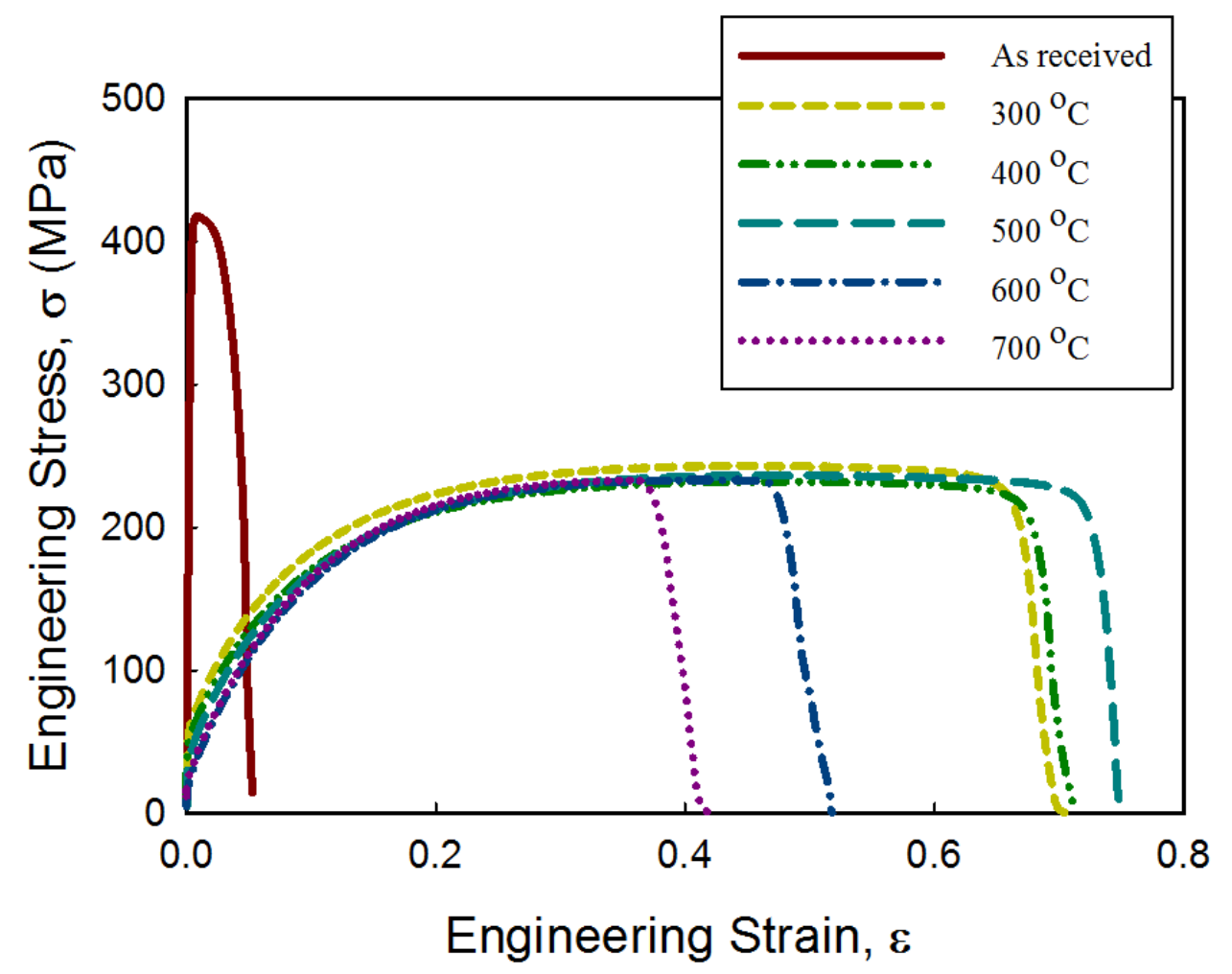

Figure 5. Tensile properties of $\mathrm{OFHC} \mathrm{Cu}$ as-received and after heat treatment 

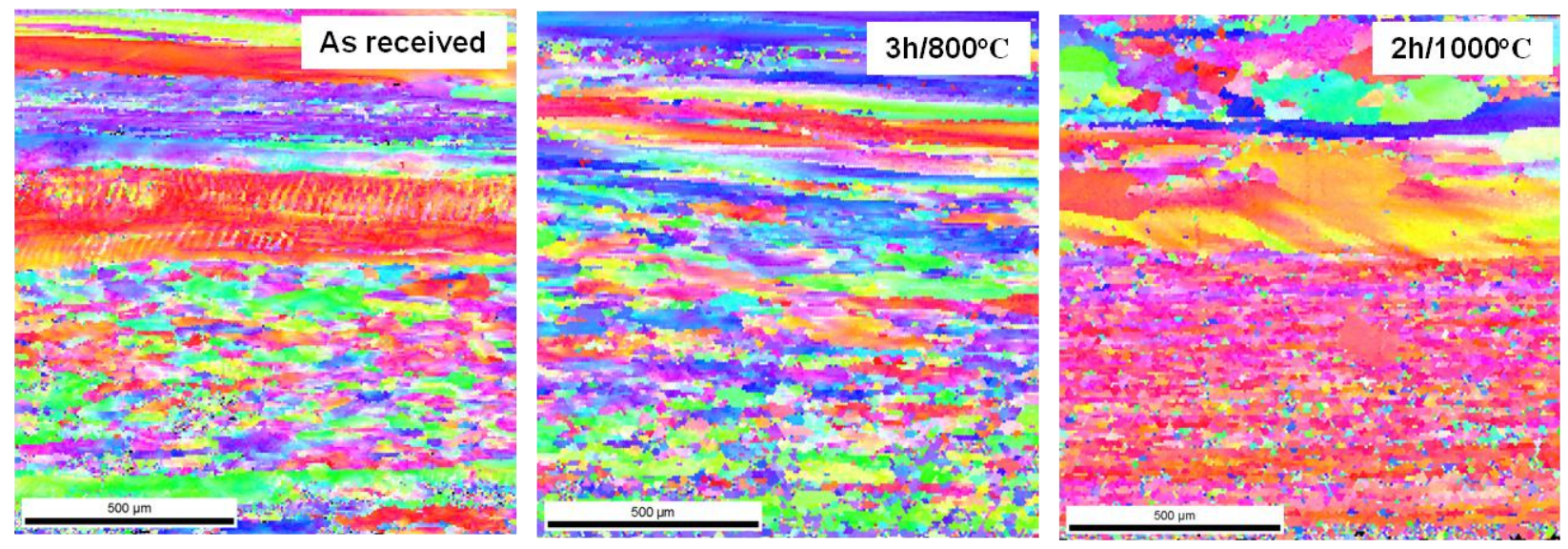

Figure 6. OIM micrographs of heat treated reacto- grade $\mathrm{Nb}$ 


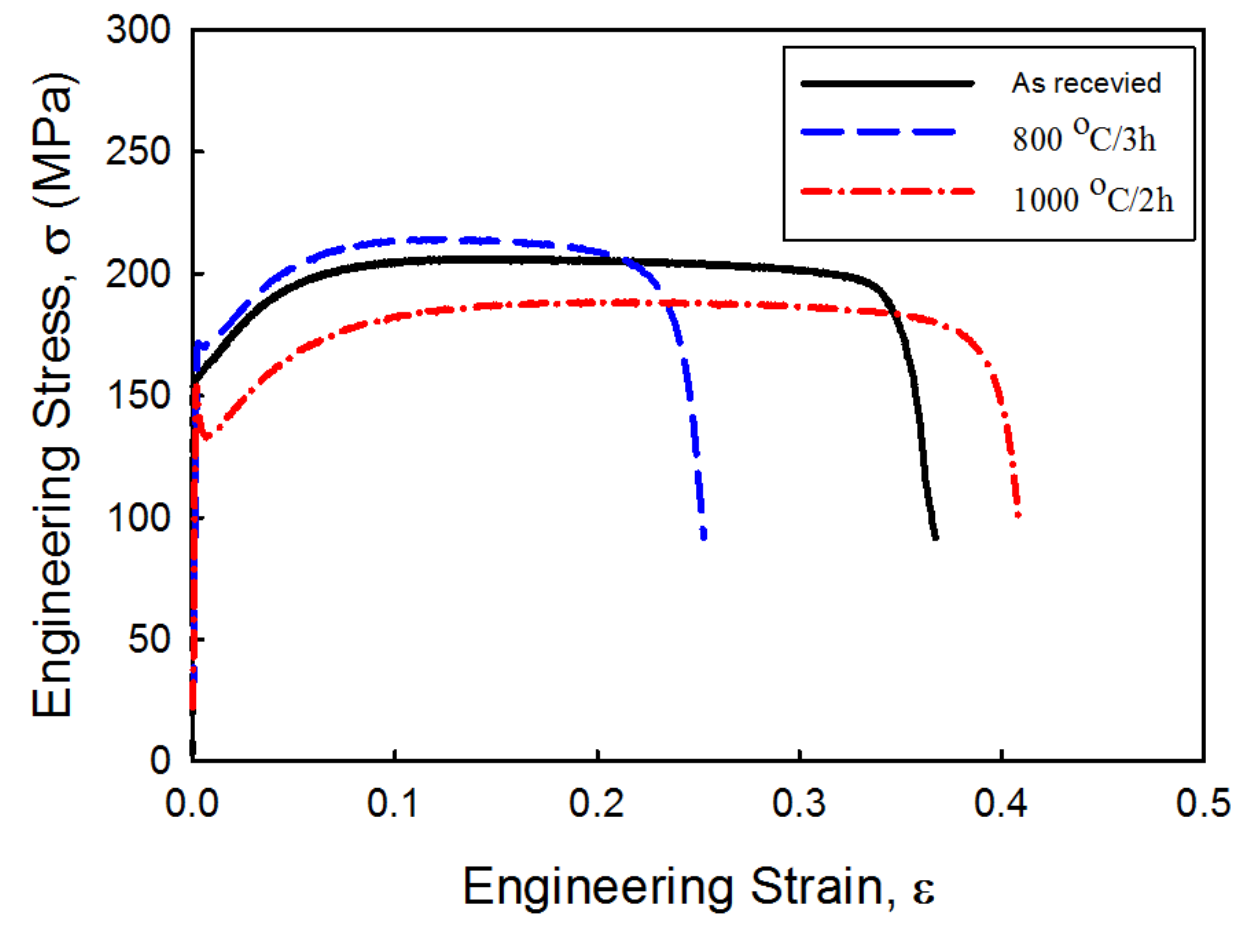

Figure 7. Tensile properties of reactor-grade $\mathrm{Nb}$ as-received and after heat treatment 


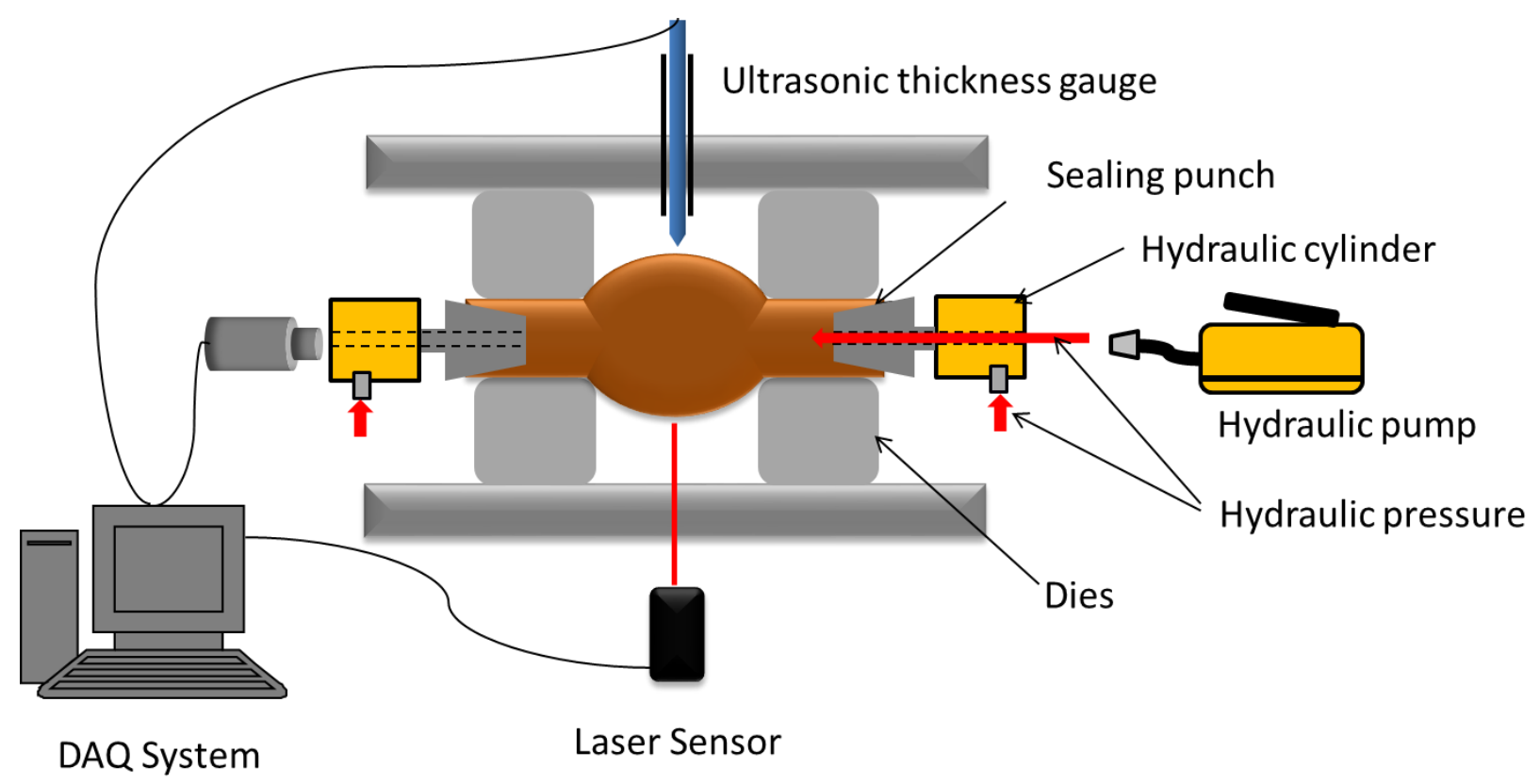

Figure 8. Schematic of the equipment assembled for bulge testing 


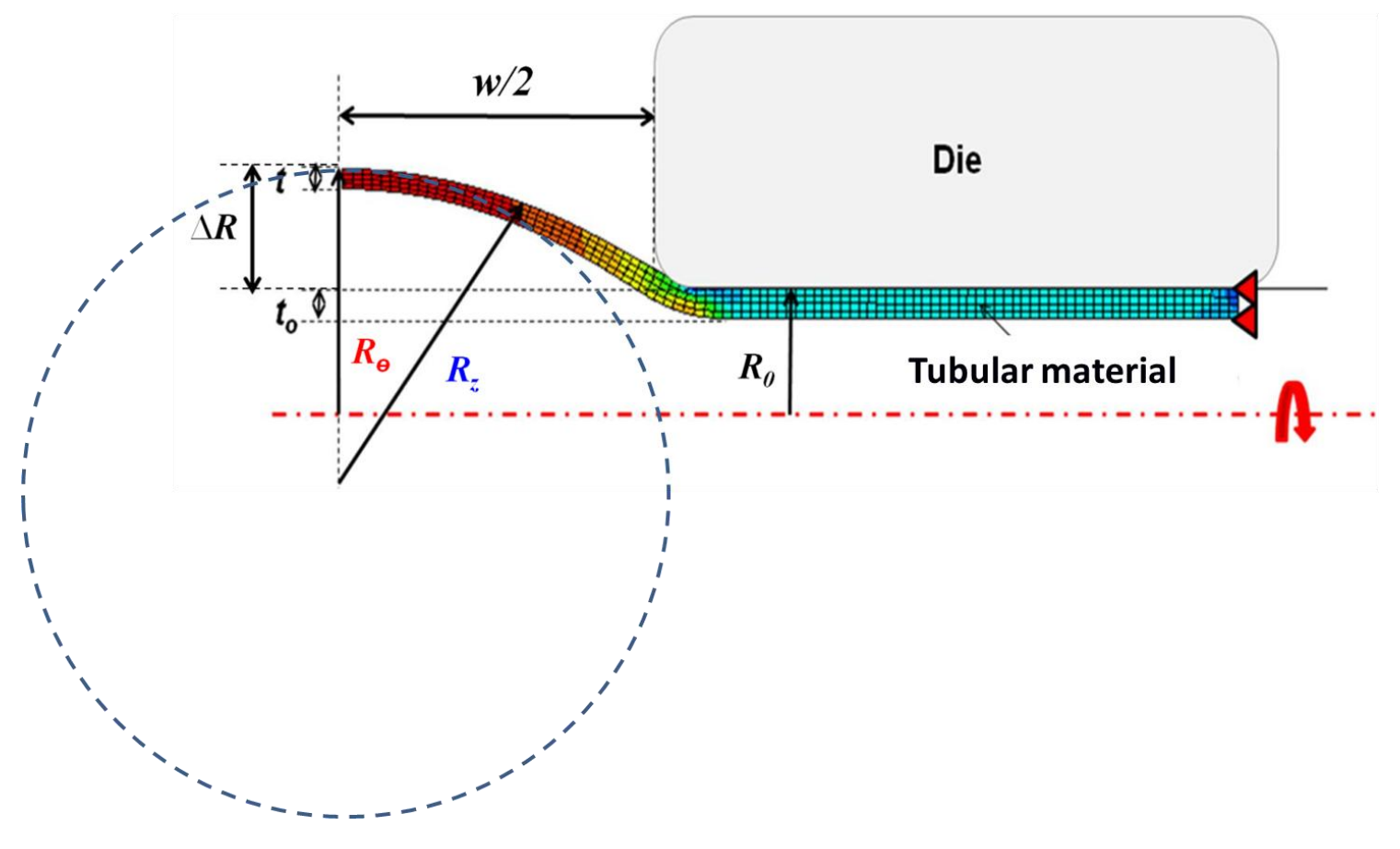

Figure 9. Parameters for analysis of the bulge test results 


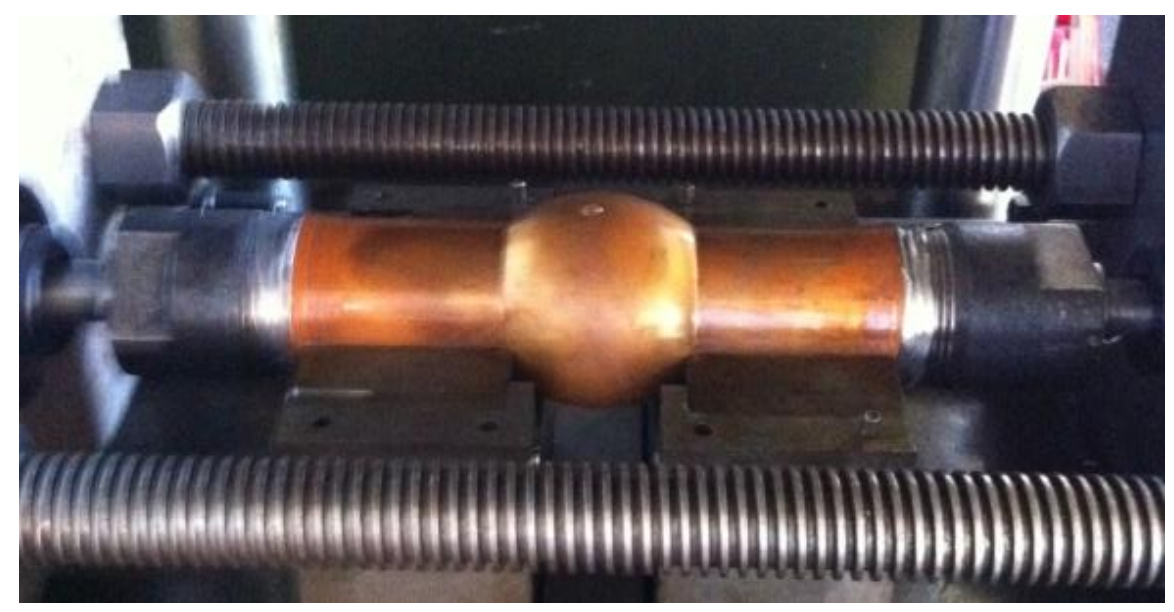

Figure 10. Bulge formed in the $\mathrm{OFHC} \mathrm{Cu}$ tube heat treated for $2 \mathrm{~h} / 500^{\circ} \mathrm{C}$ 


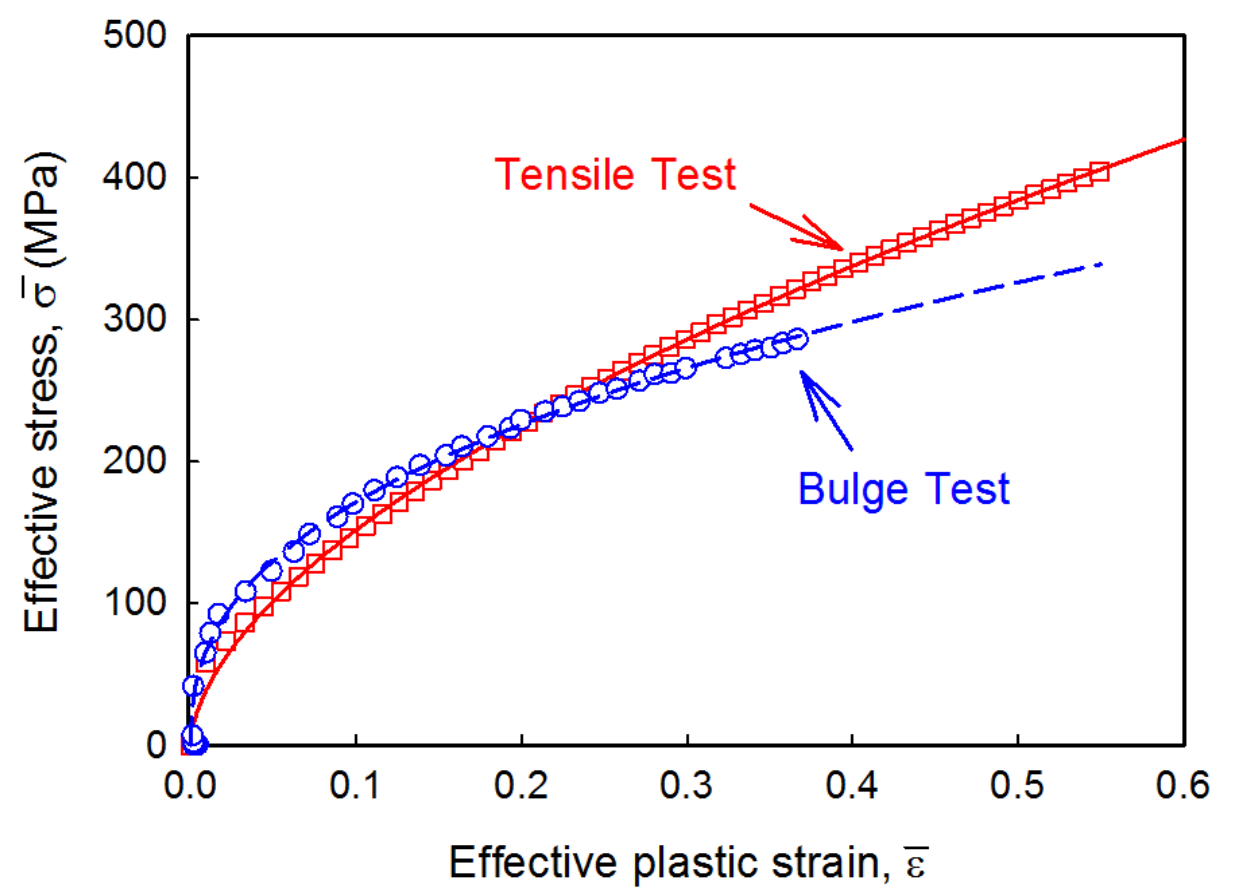

Figure 11. Effective stress/plastic strain curves for tensile- and bulge-tested heat treated OFHC $\mathrm{Cu}$ 


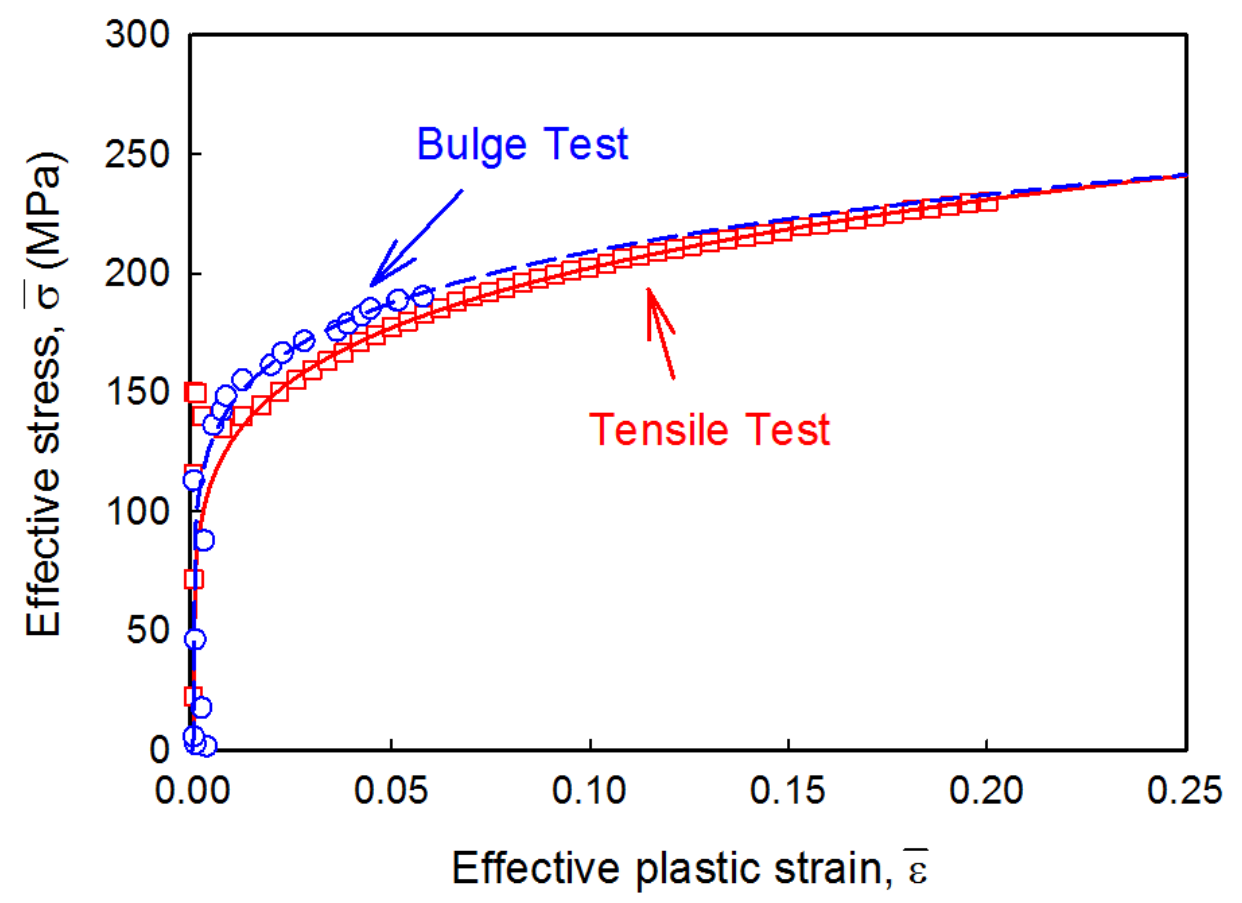

Figure 12. Effective stress/plastic strain curves for tensile- and bulge-tested heat treated reactorgrade $\mathrm{Nb}$ 

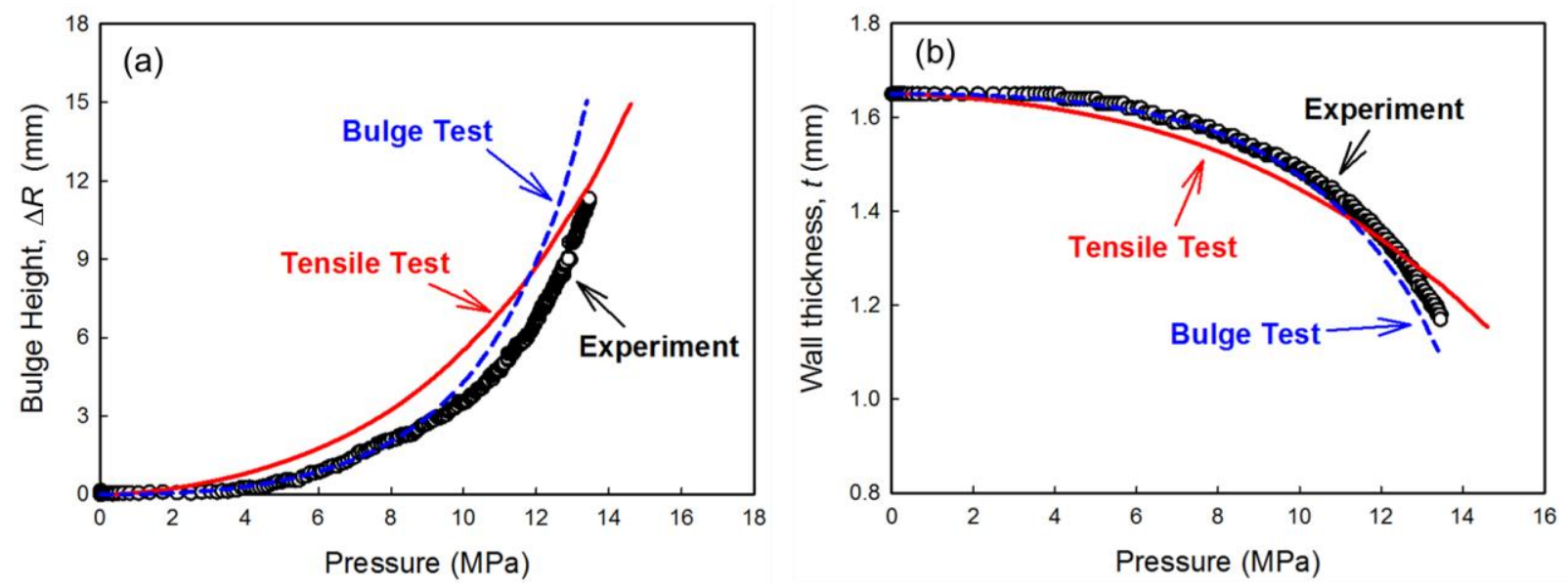

Figure 13. For OFHC Cu, comparisons of the Experimental results with simulated results based on constitutive relationships derived from the Tensile Test and the Bulge Test in terms of (a) bulge height, $\Delta R$, and (b) bulge thickness, $t$, versus applied pressure 

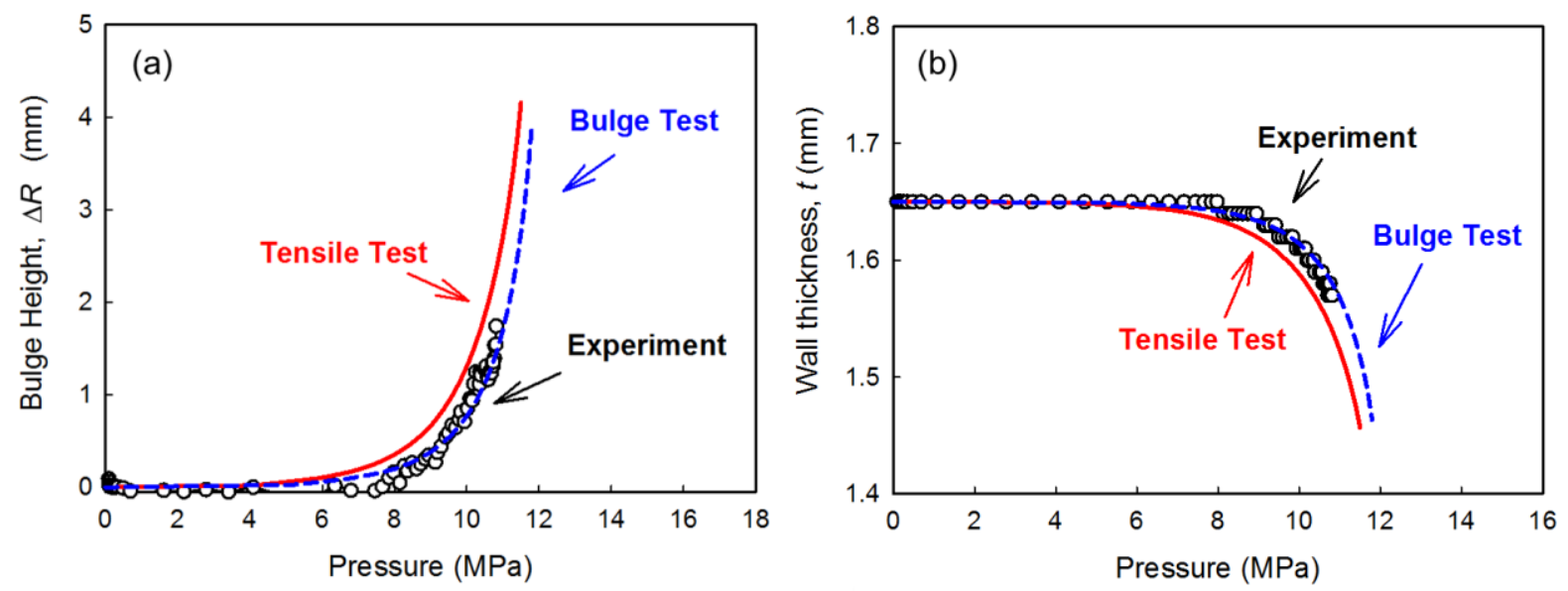

Figure 14. For reactor grade $\mathrm{Nb}$, comparisons of the Experimental results with simulated results based on constitutive relationships derived from the Tensile Test and the Bulge Test in terms of (a) bulge height, $\Delta R$, and (b) bulge thickness, $t$, versus applied pressure 